\title{
Dual-signal amplification strategy: Universal asymmetric tailing-PCR triggered rolling circle amplification assay for fluorescent detection of Cronobacter spp. in milk
}

\author{
Ju Liu, ${ }^{1}$ @ Zhongxu Zhan, ${ }^{1,2}$ Taobo Liang, ${ }^{1}$ Guoyang Xie, ${ }^{1}$ Zoraida P. Aguilar, ${ }^{3}$ and Hengyi Xu ${ }^{1 *}$ (๑) \\ ${ }^{1}$ State Key Laboratory of Food Science and Technology, Nanchang University, Nanchang, 330047, PR China \\ ${ }^{2}$ Jiangxi Institute for Food Control, Nanchang, 330001, PR China \\ ${ }^{3}$ Zystein LLC, Fayetteville, AR 72703
}

\begin{abstract}
Cronobacter spp. are important opportunistic foodborne pathogens in powdered infant formula that cause many serious diseases in neonates and infants. In this study, a novel assay based on dual signal amplification strategy was developed by coupling asymmetric tailing PCR (AT-PCR) with rolling circle amplification (RCA) for the detection of Cronobacter spp. in milk. The tailing single-stranded DNA was generated through AT-PCR and used to initiate RCA, generating tandem repetitive G-quadruplex sequences. In the presence of the fluorescence dye thioflavin $\mathrm{T}$ that could intercalate into the G-quadruplex structures, the fluorescence signal was detected with a microplate reader. The AT-PCR coupled with RCA assay was specific for Cronobacter spp. detection because of the highly specific primers chosen for the AT-PCR. The limits of detection were $4.3 \times 10^{1} \mathrm{cfu} / \mathrm{mL}$ in pure culture and $4.5 \times 10^{2} \mathrm{cfu} / \mathrm{mL}$ in spiked milk, respectively. The fixed sequences designed in the hairpin DNA allowed this AT-PCR coupled with RCA assay to serve as a universal platform for the detection of other pathogens by modifying the specificity of the PCR primers.
\end{abstract}

Key words: Cronobacter spp., rolling circle amplification, asymmetric tailing PCR, fluorescence detection

\section{INTRODUCTION}

Cronobacter spp. are important opportunistic foodborne pathogens in powdered infant formula (PIF). The genus was previously described as yellow pigmented Enterobacter cloacae because of its ability to produce a yellow pigment (Urmenyi and White Franklin, 1961). In 1980, these organisms were designated as a new species,

Received September 15, 2019.

Accepted December 8, 2019.

*Corresponding author: kidyxu@163.com or HengyiXu@ncu.edu.cn
Enterobacter sakazakii (Farmer et al., 1980). Then, it was reclassified as Cronobacter spp. This genus consists of 7 species, including Cronobacter sakazakii, Cronobacter malonaticus, Cronobacter turicensis, Cronobacter muytjensii, Cronobacter dublinensis, Cronobacter universalis, and Cronobacter condimenti (Iversen et al., 2007). According to the multi-locus sequence typing database (https://pubmlst.org/cronobacter/) reports (September 15, 2019), most isolates of Cronobacter spp. belonged to C. sakazakii $(66.92 \%)$ and C. malonaticus (11.34\%), indicating the importance of the 2 species in genus Cronobacter. Although C. sakazakii and $C$. malonaticus were mostly isolated from the environment or cases with the most severe neonatal prognosis (Ogrodzki and Forsythe, 2015), all species of Cronobacter spp. were considered to cause human illness except for C. condimenti (Cruz et al., 2011; Cruz-Córdova et al., 2012). Cronobacter spp. could cause necrotizing enterocolitis, meningitis, bacteremia, and sepsis with a 40 to $80 \%$ fatality rate in neonates $(<28 \mathrm{~d})$ and infants (Hunter et al., 2008). Many studies have identified PIF as the predominant source of neonatal infection by Cronobacter spp. and an increasing number of cases associated with PIF has been reported (Fei et al., 2015; Pei et al., 2016). The International Commission of Food Microbiology Specifications has identified Cronobacter as a severe hazard for restricted populations that could lead to life-threatening or substantial chronic sequelae or long duration (Skovgaard, 2003). The state administration for market regulation of China had proposed that Cronobacter spp. should not be present in infant formula (Chinese National Standard, 2010).

The development of an efficient and reliable method for the detection and assessment of Cronobacter spp. in PIF is of utmost importance. Traditional culture-based methods for Cronobacter spp. detection need pretreatment and selective enrichment, which are laborious (Pan et al., 2018; Song et al., 2018). To circumvent these disadvantages, many novel methods based on molecular biology techniques have been developed to 
achieve sensitive and rapid detection of Cronobacter spp. or other foodborne pathogens, such as PCR (Chen et al., 2017; Xu et al., 2017; Liang et al., 2019), loopmediated isothermal amplification (LAMP; Fan et al., 2012; Hu et al., 2018a), and strand displacement amplification (Tang et al., 2017). In the past few years, PCR has been extensively used to detect pathogens because of its simplicity. Compared with conventional PCR, quantitative PCR could provide quantitative data but requires complicated instruments and experienced operators. A more convenient, specific, and sensitive method for the accurate detection and assessment of Cronobacter spp. in dairy products has been needed.

Asymmetric PCR (aPCR) is a kind of PCR method that could produce single-stranded DNA (ssDNA) by using unequal primer concentrations. In the first 10 to 15 cycles of the PCR process, the concentration of the 2 primers (limiting primer and excess primer) is sufficient, and a symmetric PCR process occurs. When the limiting primers are consumed ( $>15$ cycles), the excess primers begin to dominate the linear amplification process, producing a large amount of ssDNA. The ssDNA amplicons produced via aPCR could be detected by agarose gel electrophoresis or used for further amplification. Moreover, although most signal amplification methods based on nucleic acid were reported and showed good sensitivity and simplicity, the application of nucleic acid signal amplification method to detect foodborne pathogens was limited because it is difficult to obtain short ssDNA from bacterial genomic double-stranded DNA. Compared with other nucleic acid-based methods that are usually designed for the detection of single-stranded DNA/RNA, the aPCR assay could provide an alternative and relatively convenient method for bacterial genomic detection (Low et al., 2013; Liu et al., 2015; Tian et al., 2018; Wang et al., 2018). The presence of ssDNA amplicons could lead to higher hybridization efficiency and detection sensitivity because of the absence of a competitive combination of complementary double strands (Wooddell and Burgess, 1996). The aPCR technique has potential for the detection of foodborne pathogens through its combination with other nucleic acid amplification or detection methods.

Rolling circle amplification (RCA) has been combined with fluorescence reagents to achieve fluorescent signal amplification (Huang et al., 2017; Zhang et al., 2019). Rolling circle amplification has been described as an isothermal enzyme-mediated amplification method for nucleic acid detection with higher sensitivity and simplicity (Liu et al., 2014). In a typical RCA process, DNA polymerase (e.g., Phi29 DNA polymerase or Bst DNA polymerase) replicates the circular template multiple times and generates a long ssDNA molecule with repetitive sequences that are complementary to the circular DNA template (Zhao et al., 2008). The RCA process could be monitored or identified by using molecular beacons (Smolina et al., 2004), fluorescent dye (Qin et al., 2018), and other transduction molecules. Before the RCA process, the RCA template could be formed after the ligation of padlock DNA or dumbbell DNA in the presence of T4 DNA ligase (Thomas et al., 1999; Qing et al., 2017) and the ligation could also be designed as a recognition portion of the whole assay to achieve specific circularization or target detection. Moreover, RCA template could be designed to form a functional DNA structure such as a G-quadruplex to achieve signal output with the help of some specific reagents (Deng et al., 2017; Huang et al., 2019; Yang et al., 2019), making it a powerful and convenient method for nucleic acid detection.

In this study, a sensor based on dual-signal amplification strategy has been developed using a combination of asymmetric tailing PCR (AT-PCR) with RCA, AT-PCR + RCA. A circular DNA template with complementary G-quadruplex DNA sequence could be obtained via the ligation of pre-designed hairpin DNA. The tailed ssDNA amplicons that were obtained from AT-PCR could initiate the RCA process to form G-quadruplex DNA structures. With the addition of G-quadruplex-specific fluorescent dye thioflavin $\mathrm{T}$ (ThT), which intercalated with the G-quadruplex DNA structures, fluorescence signals could be detected with a microplate reader. Owing to the fixed initial sequence in the RCA template, the strategy was applicable to detect other pathogens or ssDNA without altering the hairpin DNA sequence, making it a low-cost and universal platform for pathogen detection. The AT-PCR + RCA sensor showed good detection sensitivity, specificity, and universality with great potential application in pathogen detection.

\section{MATERIALS AND METHODS}

\section{Materials and Reagents}

Primers and hairpin DNA used in this experiment were purchased from Tsingke Biological Co. Ltd. (Beijing, China). The DNA sequences were listed in Table 1. The relevant characterization information of hairpin DNA was shown in Supplemental Figure S1 (https:// doi.org/10.3168/jds.2019-17590). The sequence of hairpin DNA was validated by The Nucleic Acid Package analysis software (http://www.nupack.org) to guarantee the absence of undesired mismatch and structures (Supplemental Figure S2; https://doi.org/10.3168/ jds.2019-17590). The sequences of ompA (outer membrane protein, ompA) gene (GenBank: GQ845410.1) 
Table 1. Oligonucleotide sequences used in this assay ${ }^{1}$

\begin{tabular}{|c|c|c|c|}
\hline DNA & Sequence $\left(5^{\prime}-3^{\prime}\right)$ & $\begin{array}{l}\text { Amplicon } \\
\text { size (bp) }\end{array}$ & Reference \\
\hline Hairpin DNA & $\begin{array}{l}\text { Phosphate-CAGAACAGGTTTAAAAAAAAAAAAAAAAAAAAACCCAACCC } \\
\text { GCCCTACCCTTTCCTGTTCTG }\end{array}$ & NA & This study \\
\hline OmpA-R & AAAAAAAAAAAAAAAAAAAAATGGATTCGCCCATACCACGTGC & & \\
\hline $\mathrm{P} 1$ & TTTTTTTTTTTTTTTTTTTTT & NA & This study \\
\hline
\end{tabular}

${ }^{1} \mathrm{~F}=$ forward $\mathrm{R}=$ reverse; $\mathrm{NA}=$ not available. Underlined sequences represent complementary region of $\mathrm{P} 1$.

of Cronobacter spp. were downloaded from National Center for Biotechnology Information database (http:/ /www.ncbi.nlm.nih.gov/). The specific primers targeting ompA gene of Cronobacter spp. for AT-PCR assay were selected based on multiple sequences alignment analysis (Supplemental Figure S3; https://doi.org/10 $.3168 /$ jds.2019-17590) using ClustalW algorithm in MEGAX (Kumar et al., 2018) and designed following the rules of linear-after-the-exponential PCR principles described by Pierce et al. (2005) to maximize AT-PCR efficiency. The nucleotides and oligonucleotides were dissolved in sterilized ultrapure water $\left(18.3 \Omega \mathrm{cm}^{-1}\right.$, Millipore, Bedford, MA) and stored at $-20^{\circ} \mathrm{C}$. The T4 DNA ligase $(5 \mathrm{U} / \mu \mathrm{L})$, Phi29 DNA polymerase $(10 \mathrm{U} /$ $\mu \mathrm{L})$, DL500 DNA marker, DL5000 DNA marker, and dNTP mixture $(2.5 \mathrm{mM})$ were purchased from Sangon Biotech Co. Ltd. (Shanghai, China). Two $\times$ Taq Master Mix (Dye) for PCR was purchased from Novoprotein Technology Co. Ltd. (Shanghai, China). Bovine serum albumin and ThT were purchased from Sigma-Aldrich (St. Louis, MO). The agarose was obtained from Solai Bao Technology Co. Ltd. (Beijing, China). All reagents used were of analytical grade.

\section{Bacterial Strain Information}

The target strains belonging to Cronobacter spp. were C. sakazakii ATCC29544, C. muytjensii ATCC51329, C. turicensis CICC24178, C. condimenti CICC24184, C. dublinensis ssp. dublinensis CICC24179, C. malonaticus CMCC45402, and C. universalis NCTC9529. Nontarget strains, including Staphylococcus aureus CMCC26001, Pseudomonas aeruginosa CMCC10104, Listeria monocytogenes ATCC13932, Listeria monocytogenes CMCC54007, Listeria seeligeri ATCC35967, Salmonella Typhi JX-CDC40002 (Jiang Xi Province Center for Disease Control and Prevention, Nanchang, China), Salmonella Enteritidis ATCC13076, Salmonella Typhimurium ATCC13311, Escherichia coli ATCC25722, Escherichia coli O157:H7 CMCC44828, Escherichia coli O157:H7 ATCC43888, Bacillus cereus ATCC14579, Franconibacter pulveris LMG24057, Franconibacter helveticus LMG23732, and Siccibacter turicensis
LMG23730 were used to validate the specificity of the assay. Strains were revived and grown in Luria-Bertani medium at $37^{\circ} \mathrm{C}$ in a rotary shaker at $180 \mathrm{rpm}$ for overnight. Plate count assay using Luria-Bertani medium for the determination of bacterial concentrations was followed by serial dilutions with sterile PBS $(0.01 \mathrm{M}$, $\mathrm{pH}$ 7.4) and incubation at $37^{\circ} \mathrm{C}, 12 \mathrm{~h}$.

\section{Sample Preparation}

Genomic DNA of C. sakazakii ATCC29544 was extracted with the boiling method. One milliliter of overnight culture was centrifuged at $12,000 \times g$ for 5 min at room temperature. The pellet was washed twice with PBS and resuspended with $50 \mu \mathrm{L}$ of sterilized ultrapure water and placed in a water bath for $15 \mathrm{~min}$. After centrifugation at $12,000 \times g$ for $5 \mathrm{~min}$ at room temperature, genomic DNA was obtained from the supernatant. Then AT-PCR was applied to generate and amplify the ssDNA from bacterial genomic DNA. A total of $50 \mu \mathrm{L}$ of the AT-PCR reaction contained $25 \mu \mathrm{L}$ of $2 \times$ Taq Master Mix, $3 \mu \mathrm{L}$ of genomic DNA, $1 \mu M$ forward $o m p A$ primer, $0.2 \mu M$ reverse ompA primer, and then $16 \mu \mathrm{L}$ of sterilized ultrapure water was added. The AT-PCR process was initiated with $95^{\circ} \mathrm{C}$ for 10 min, followed by 40 cycles of $95^{\circ} \mathrm{C}$ for $30 \mathrm{~s}, 60^{\circ} \mathrm{C}$ for 30 $\mathrm{s}$ and $72^{\circ} \mathrm{C}$ for $30 \mathrm{~s}$, and final elongation at $72^{\circ} \mathrm{C}$ for 10 min.

\section{Formation of the Dumbbell-Like DNA from Hairpin DNA}

The RCA template, circular probe (dumbbell-like DNA) could be formed between 2 hairpin DNA molecules by the ligation of T4 DNA ligase. Before the ligation, the hairpin DNA was heated at $95^{\circ} \mathrm{C}$ for 5 min, then the mixture was cooled to room temperature, which allowed the formation of the desired hairpin structure. Ligation process was performed in a total of $100 \mu \mathrm{L}$ volume reaction that contained $10 \mu \mathrm{L}$ of hairpin DNA $(1 \mu M), 8 \mu \mathrm{L}$ of T4 DNA ligase, $10 \mu \mathrm{L}$ of $10 \times$ T4 DNA ligase reaction buffer, and $72 \mu \mathrm{L}$ of sterilized ultrapure water. The reaction was carried in a thermal 
cycler at $22^{\circ} \mathrm{C}$ for $2 \mathrm{~h}, 65^{\circ} \mathrm{C}$ for 10 min to inactivate the ligase and terminate the ligation. The dumbbell-like DNA was either directly used or stored at $-20^{\circ} \mathrm{C}$.

\section{RCA Assay and Fluorescent Detection}

The RCA assay for signal amplification was performed by using AT-PCR amplicons or synthetic polyT oligonucleotide primer P1 (Table 1). A $50-\mu \mathrm{L}$ volume of the RCA reaction contained $12.5 \mu \mathrm{L}$ of dumbbelllike DNA, $10 \mu \mathrm{L}$ of AT-PCR amplicons or primer P1, $1 \mu \mathrm{L}$ of phi29 DNA polymerase $(10 \mathrm{U} / \mu \mathrm{L}), 5 \mu \mathrm{L}$ of $10 \times$ phi29 DNA polymerase reaction buffer, $5 \mu \mathrm{L}$ of $\operatorname{dNTP}(2.5 \mathrm{mM}), 2.5 \mu \mathrm{L}$ of BSA $(100 \mu \mathrm{g} / \mathrm{mL}), 1 \mu \mathrm{L}$ of ThT $(1 \mathrm{mM})$, and $10.5 \mu \mathrm{L}$ of sterilized ultrapure water. The reaction mixture was incubated at $30^{\circ} \mathrm{C}$ for $3 \mathrm{~h}$ and transferred to a microplate (black) for fluorescent detection. Fluorescence intensities were determined using a Varioskan multimode microplate reader (Thermo Fisher Scientific, Waltham, MA). The excitation wavelength was set at $425 \mathrm{~nm}$ and the emission wavelength was measured at a range between 450 to $600 \mathrm{~nm}$.

\section{Agarose Gel Electrophoresis Analysis}

The formation of the dumbbell-like DNA and RCA products were analyzed in agarose gel $5 \%$ for dumbbell-like DNA and 1\% for RCA products) electrophoresis with $1 \times$ TAE buffer (0.04 $M$ Tris-acetate, $2 \mathrm{~m} M$ EDTA, $\mathrm{pH} 8.5)$ at $70 \mathrm{~V}$ for $50 \mathrm{~min}$ at room temperature. The results were visualized and captured by ImageQuant LAS 500 (GE Healthcare Bio-Sciences, Pittsburgh, PA).

\section{Limit of Detection and Specificity of the Proposed Strategy in Pure Culture}

The limit of detection (LOD) of the method was tested with a 10-fold C. sakazakii ATCC29544 fresh pure culture dilution series ranging from $4.3 \times 10^{6}$ to $4.3 \times 10^{1} \mathrm{cfu} / \mathrm{mL}$. Genomic DNA extraction, AT-PCR, and RCA with fluorescence detection were performed as described above. Moreover, other target strains belonging to Cronobacter spp. and nontarget strains were also tested to verify the specificity of the method.

\section{Detection of C. sakazakii in Artificial Contaminated Milk}

To validate the feasibility of the AT-PCR + RCA sensor in real milk matrix samples, $1 \mathrm{~g}$ of sterile skim milk powder was dissolved in $9 \mathrm{~mL}$ of PBS to obtain a $10 \%$ skim milk powder matrix (milk matrix). A total of $50 \mu \mathrm{L}$ of various concentrations of C. sakazakii fresh pure culture were added to every $450-\mu \mathrm{L}$ milk matrix to get bacterial final concentrations ranging from $4.5 \times$ $10^{6}$ to $4.5 \times 10^{0} \mathrm{cfu} / \mathrm{mL}$. After genomic extraction, the AT-PCR coupled with RCA assay was performed to assess the LOD in the milk matrix.

\section{RESULTS AND DISCUSSION}

\section{Experimental Principle}

The schematic of the proposed strategy for the detection of Cronobacter spp. in milk was illustrated in Figure 1. The 5'-end phosphorylated hairpin DNA was designed for RCA samples. Its sequence contained 3 parts: primer binding region (21-adenine), complementary sequences for the G-quadruplex, and complementary double-stranded stem sequences. The entire assay includes 3 parts: (a) ligation of the hairpin DNA to form the dumbbell-like DNA, (b) AT-PCR assay to obtain target ssDNA amplicons, and (c) the target ssDNA combined with dumbbell-like DNA to initiate the RCA process. (a) The dumbbell-like DNA was preformed using T4 DNA ligase to ligate the 2 hairpin DNA after which the T4 DNA ligase was inactivated to eliminate possible interference with phi29 DNA polymerase. (b) Genomic DNA of C. sakazakii obtained by boiling the samples in water bath was used for the AT-PCR. The specific primer targeted the ompA gene of Cronobacter spp., whereas the $5^{\prime}$-end of the reverse primer was tailed with 21-adenine. (c) After the AT-PCR amplification of the genomic DNA, the short ssDNA amplicons that were tailed with 21-thymine could partly bind to the primer binding region of the dumbbell-like DNA. This binding resulted in the initiation of the RCA process, which generated a long and repeated ssDNA that contained G-quadruplex sequences that resulted from the 21 -adenine from the $5^{\prime}$-end of the reverse primer. In the presence of fluorescence dye $\mathrm{ThT}$ and $\mathrm{K}^{+}$, the repeated G-quadruplex structures could be formed and ThT intercalated into the G-quadruplex structures with high affinity that resulted in significant fluorescence enhancement that was excited at $425 \mathrm{~nm}$ and emitted at $490 \mathrm{~nm}$ (Mohanty et al., 2013).

\section{Feasibility of the Proposed Strategy}

Agarose gel electrophoresis with ethidium bromide stain and microplate fluorescence detection were carried out to confirm the results at the various stages in the development of the AT-PCR coupled with RCA assay. Initially, gel electrophoresis was used to follow the ligation process that formed the dumbbell-like 


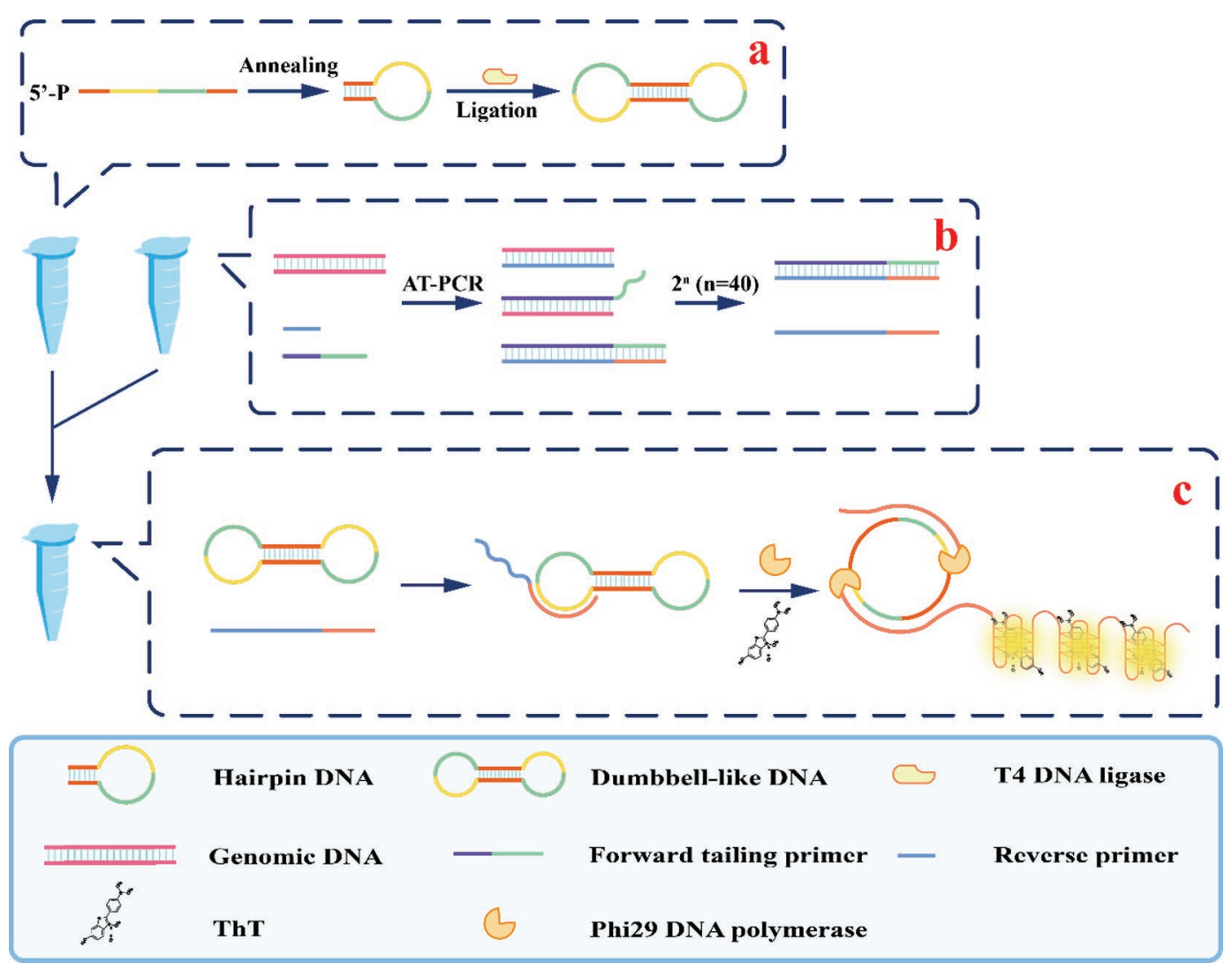

Figure 1. Schematic illustration of the asymmetric tailing PCR (AT-PCR) coupled with rolling circle amplification (RCA) assay for the detection of Cronobacter spp. ThT $=$ fluorescence dye thioflavin $\mathrm{T}$.

DNA. As shown in Figure 2, in the presence of T4 DNA ligase, a new distinct band of dumbbell-like DNA (lane 2) with slower mobility than the hairpin DNA (lane 1) was observed in 5\% agarose gel, indicating the ligation between the 2 hairpin DNA to form the dumbbell-like DNA. After ligation, RCA was carried out with a synthetic primer P1 that resulted in a visible and distinct fluorescence signal that was obtained only in the presence of both dumbbell-like DNA and P1, as shown in Figure 3A, suggesting that P1 could trigger the RCA process and generated the G-quadruplex sequences. The ThT intercalation, which resulted in fluorescence signal, was used to confirm the formation of G-quadruplex. However, a mild fluorescence signal was observed when the reaction mixture contained dumbbell-like DNA, which could have resulted in the random and nonspecific amplification of phi29 DNA polymerase in the presence of dNTP.

A $1 \%$ gel electrophoresis was performed to confirm the initiation of the RCA process. As shown in Figure $3 \mathrm{~B}$, the RCA products (lane 3 ) exhibited a significant fluorescence signal, suggesting successful initiation of the RCA process. These results indicated that the hairpin DNA formed the dumbbell-like DNA and the

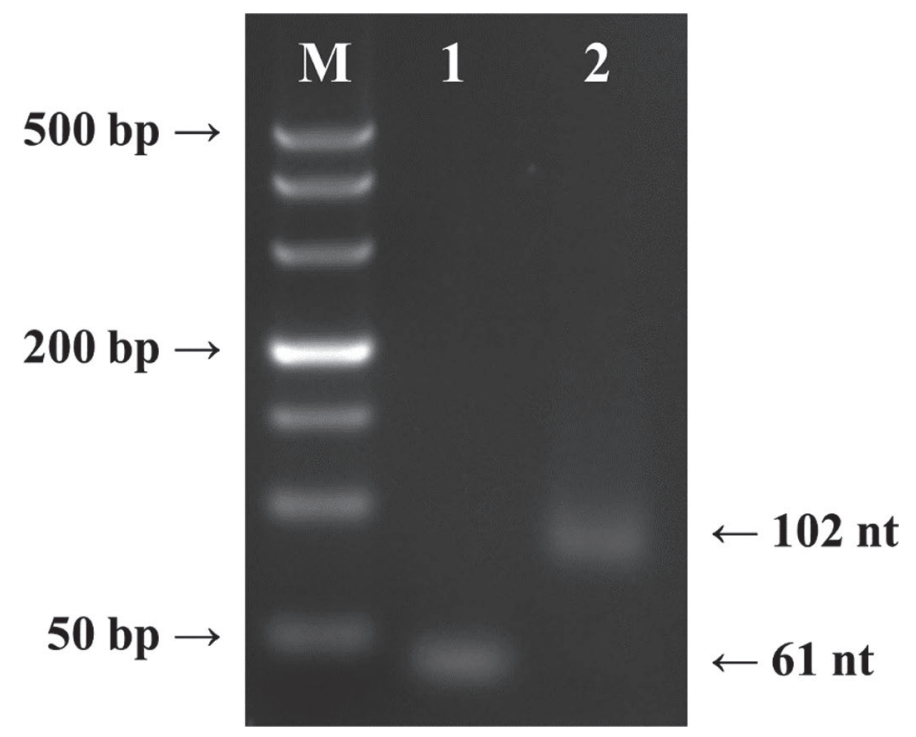

Figure 2. Agarose gel electrophoresis verification of the dumbbelllike DNA formation. Lane M: DL500 DNA Marker (Sangon Biotech Co. Ltd., Shanghai, China); lane 1: hairpin DNA $(1 \mu M)$; and lane 2: hairpin DNA $(1 \mu M)+$ T4 DNA ligase + T4 DNA ligase buffer. 
A

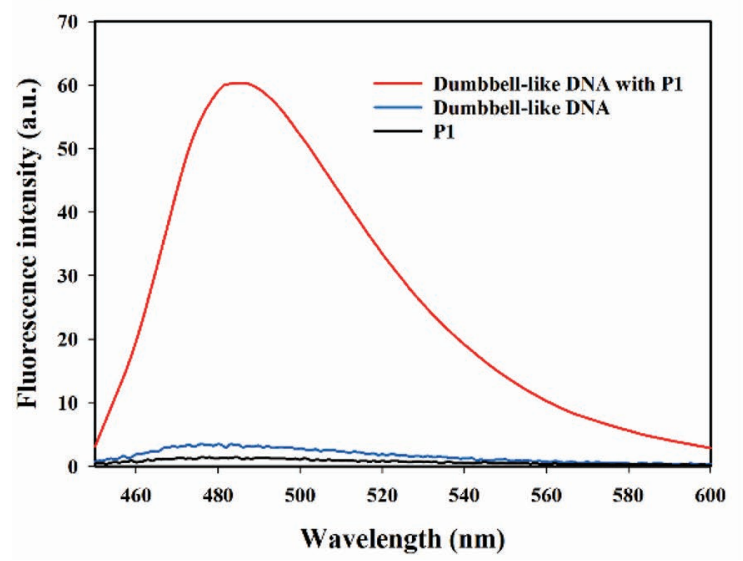

B

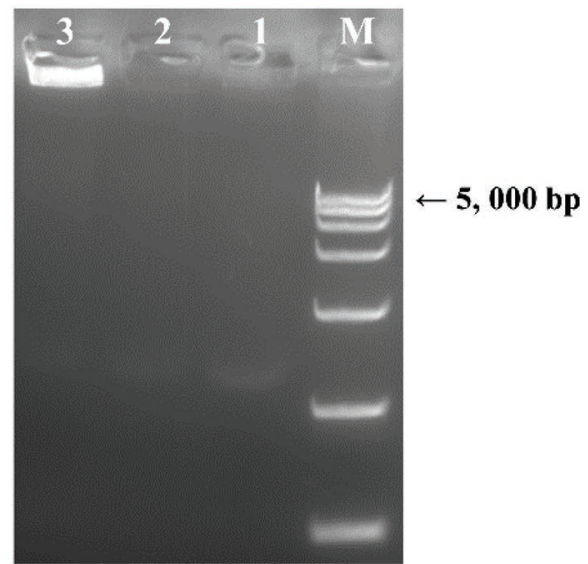

Figure 3. Verification of the rolling circle amplification (RCA) process using primer P1. (A) Fluorescence verification of the RCA process using (a) dumbbell-like DNA with primer P1, (b) dumbbell-like DNA, and (c) primer P1. (B) Agarose gel electrophoresis verification of the RCA process. Lane M: DL5000 DNA Marker (Sangon Biotech Co. Ltd., Shanghai, China); lane 1: RCA system with primer P1; lane 2: RCA system with dumbbell-like DNA; and lane 3: RCA system with dumbbell-like DNA and primer P1. a.u. = arbitrary units.

RCA process was initiated successfully in the presence of primer $\mathrm{P} 1$.

\section{Optimization of Conditions}

To obtain optimized conditions for the AT-PCR + RCA sensor, the concentrations of the dumbbell-like DNA and ThT were optimized using $\mathrm{P} 1$ at $1 \mu M$ as the RCA initiator. As shown in Figure 4A, when the concentration of the dumbbell-like DNA was set from 200 to $350 \mathrm{n} M$, the fluorescence signal was increased and reached a plateau at $250 \mathrm{nM}$. So, the optimized concentration of dumbbell-like DNA in this assay was $250 \mathrm{nM}$. When the concentration of ThT was set from 2.5 to $30 \mu M$, the fluorescence signal increased and finally reached a plateau at $20 \mu M$. Hence, the optimized concentration of ThT that was used in the succeeding assays was $20 \mu M$ (Figure 4B).

\section{AT-PCR Efficiency Optimization}

The primers for AT-PCR assay were designed following the principle described in by Pierce et al. to achieve relatively maximal aPCR efficiency. The melting temperature of limiting primer $\left(70.1^{\circ} \mathrm{C}\right)$ is higher than that of excess primer $\left(63.5^{\circ} \mathrm{C}\right)$, so the efficiency of the linear phase of AT-PCR can be improved. The detailed design principle can be found in this previous study (Pierce et al., 2005).

Since the ratio of forward primer and reverse primer was a critical parameter of the AT-PCR assay, it was optimized to improve the efficiency of the AT-PCR

\section{A}

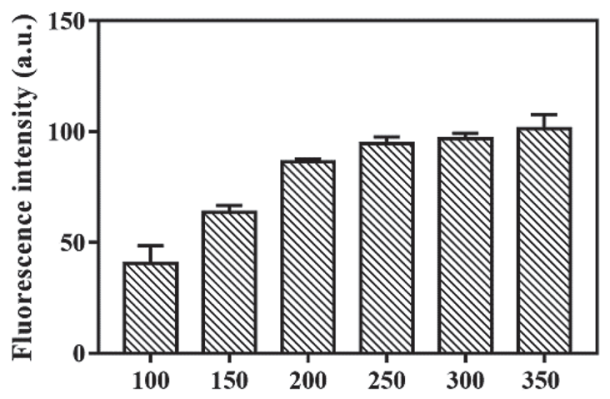

The concentration of dumbbell-like DNA (nM)
B

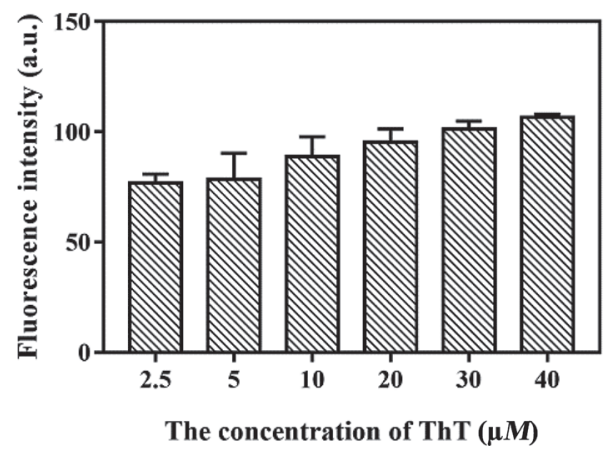

Figure 4. Optimization of the concentrations of (A) dumbbell-like DNA and (B) fluorescence dye thioflavin T (ThT). The fluorescence intensities were measured at emission wavelength $=490 \mathrm{~nm}$. a.u. = arbitrary units. Error bars indicate the SD from 3 representative experiments. 


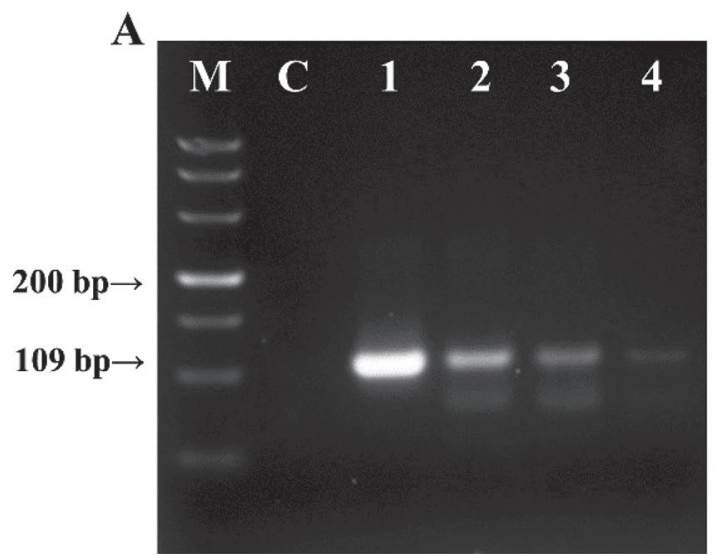

\section{B}

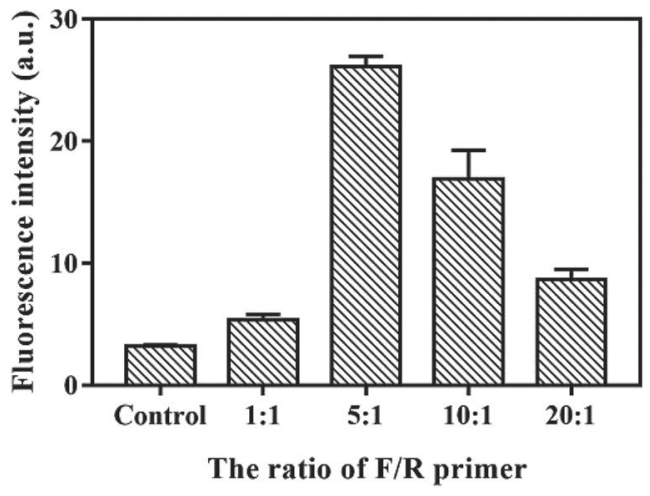

Figure 5. Optimization of the asymmetric tailing PCR (AT-PCR) forward/reverse (F/R) primer ratio. (A) Agarose gel electrophoresis verification. Lane M: DL500 DNA Marker (Sangon Biotech Co. Ltd., Shanghai, China); lane C: control; lane 1: primer ratio of F/R was 1:1; lane 2: primer ratio of $\mathrm{F} / \mathrm{R}$ was 5:1; lane 3: primer ratio of $\mathrm{F} / \mathrm{R}$ was 10:1; and lane 4: primer ratio of $\mathrm{F} / \mathrm{R}$ was 20:1. (B) Fluorescence detection. The fluorescence intensities were measured at emission wavelength $=490 \mathrm{~nm}$. a.u. $=$ arbitrary units. Error bars indicate the SD from 3 representative experiments.

assay. As shown in Figure 5A, AT-PCR with various ratios of forward and reverse primers $(\mathbf{F} / \mathbf{R})$ were set at 1:1, 5:1, 10:1, and 20:1 to optimize the F/R. Using unequal $\mathrm{F} / \mathrm{R}$ ratios generated bright bands of ssDNA at 5:1 and 10:1, which was consistent with our previous studies in the aPCR assay, but the bands presented in this AT-PCR assay were brighter (data not shown). To further evaluate the optimal $\mathrm{F} / \mathrm{R}$ ratio, $\mathrm{RCA}$ was performed. In Figure $5 \mathrm{~B}$, when the ratio of $\mathrm{F} / \mathrm{R}$ was $5: 1$, the fluorescence intensity was the highest, indicating this to be the best $\mathrm{F} / \mathrm{R}$ ratio among the conditions tested. This also indicated that the AT-PCR products initiated the RCA process and generated G-quadruplex DNA sequences.

\section{Performance Analysis of the Strategy}

The sensitivity of the AT-PCR + RCA sensor was validated using the optimized conditions as described above. C. sakazakii ATCC29544 overnight pure culture (about $4.3 \times 10^{9} \mathrm{cfu} / \mathrm{mL}$ ) was diluted into a 10-fold dilution series ranging from $4.3 \times 10^{6}$ to $4.3 \times 10^{1} \mathrm{cfu} /$ mL. Genomic DNA extraction, aPCR assay, and RCA assay were followed, and fluorescence intensities were collected with a microplate reader. As shown in Figure $6 \mathrm{~A}$, the fluorescence intensity increased with increasing concentrations of C. sakazakii. A linear relationship between the fluorescence intensity and the concentration of C. sakazakii was achieved over a dynamic range from $4.3 \times 10^{6}$ to $4.3 \times 10^{1} \mathrm{cfu} / \mathrm{mL}$. The linear regression equation (Figure 6B) in pure culture was given by $\mathrm{y}=4.151 \mathrm{x}-1.187\left(\mathrm{R}^{2}=0.9562\right)$, where $\mathrm{y}=$ the fluorescence intensity measured at $490 \mathrm{~nm}$ and $\mathrm{x}=$ the $\log$ concentration of C. sakazakii. Based on the cut-off value (mean $+3 \mathrm{SD}$ of the control group), the $\mathrm{LOD}$ of the proposed strategy in pure culture was $4.3 \times 10^{1}$ $\mathrm{cfu} / \mathrm{mL}$.

\section{Specificity and Universality Evaluation}

To determine the specificity of the proposed strategy, several common foodborne pathogens and species belonging to Cronobacter (with concentrations of $10^{6} \mathrm{cfu} /$ $\mathrm{mL}$ ) were analyzed using the optimized parameters. As shown in Figure 7, the group containing Cronobacter spp. (Figure 7A) showed higher fluorescence intensities than control group, but the nontarget bacteria (Figure 7B) showed similar fluorescence intensities with the control group, indicating that the AT-PCR amplicons from the nontarget bacteria tested could not initiate the RCA process. These results indicated that the components of the AT-PCR + RCA sensor developed in this study were highly specific for the detection of Cronobacter spp. The specificity of this assay was resulting from the highly specific primers chosen for the AT-PCR. As a Cronobacter species-specific gene, the omp $A$ gene has been widely used as a target for the detection of Cronobacter spp. in PIF with high specificity and sensitivity (Chen et al., 2017; Liu et al., 2018). These studies indicated that $o m p A$ gene exists in all the 7 species of Cronobacter. However, due to the absence of a suitable variable domain in the omp $A$ gene, the AT-PCR primers designed in this assay are not applicable for the identification of Cronobacter species, making it a weakness of this method (Hu et al., 2018b).

Furthermore, to verify the universality of the ATPCR + RCA sensor, some other foodborne pathogens including Pseudomonas aeruginosa CMCC10104, 
A

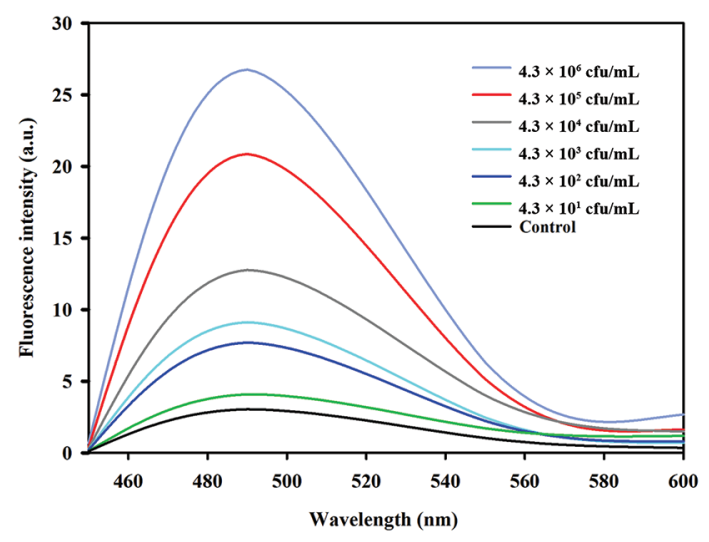

B

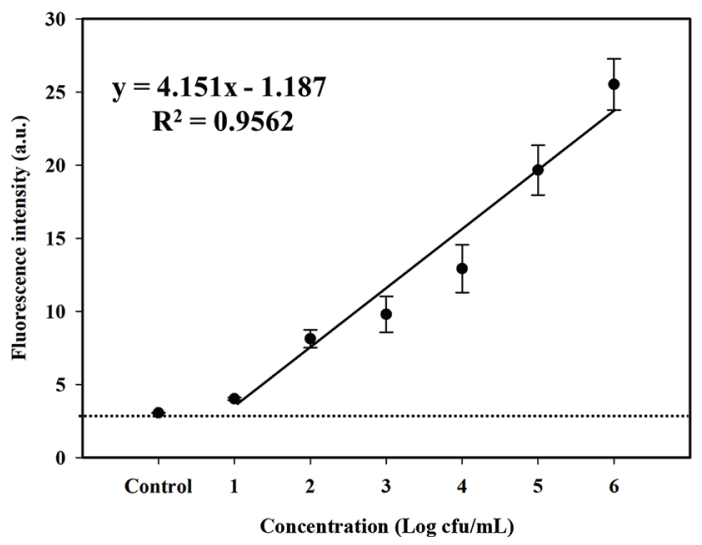

Figure 6. (A) Fluorescent signal response with different concentrations of Cronobacter sakazakii in pure culture ranging from $4.3 \times 10^{6}$ to $4.3 \times 10^{1} \mathrm{cfu} / \mathrm{mL}$. (B) The calibration curves of the $\log$ C. sakazakii concentrations $(\mathrm{cfu} / \mathrm{mL})$ with corresponding fluorescence intensities. The fluorescence intensities were measured at emission wavelength $=490 \mathrm{~nm}$. The dashed line represents the cut-off value. Error bars indicates the SD from 3 representative experiments. a.u. $=$ arbitrary units.

Escherichia coli O157:H7 ATCC43888, and Salmonella Enteritidis ATCC13076 were detected. Three pairs of primers (Supplemental Table S1; https://doi.org/10 $.3168 /$ jds.2019-17590) were selected based on their specific genes, respectively, and modified with 21-adenine (forward or reverse primer); the position of the 21-adenine depended on their efficiency in AT-PCR (data not shown). Distinct fluorescent signals could be observed in all 3 pathogens compared with the control group, as shown on Supplemental Figure S4 (https://doi.org/ 10.3168/jds.2019-17590). This indicated that the ATPCR + RCA sensor has the potential to be a universal platform for the detection of foodborne pathogens with modifications to the primers.

\section{Detection of C. sakazakii in Artificially Contaminated Milk Sample}

The feasibility of the proposed strategy in spiked milk matrix was demonstrated using serial concentrations of C. sakazakii. As shown in Figure 8A, the fluorescent intensities increased with increasing $C$. sakazakii concentrations in the spiked milk matrix containing $4.5 \times$ $10^{6}$ to $4.5 \times 10^{0} \mathrm{cfu} / \mathrm{mL}$. A linear relationship (Figure

A

B

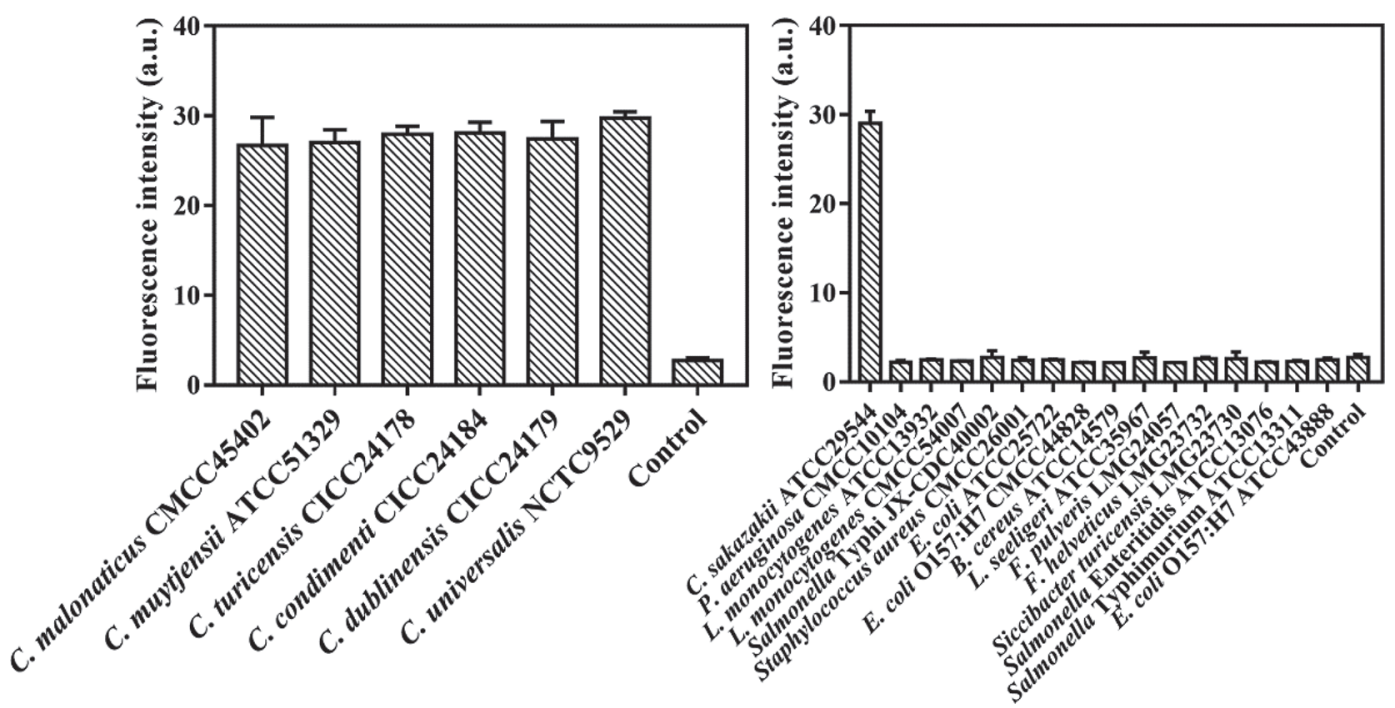

Figure 7. Specificity verification with (A) target Cronobacter spp. strains and (B) nontarget strains. The fluorescence intensities were measured at emission wavelength $=490 \mathrm{~nm}$. a.u. = arbitrary units. Error bars indicate the SD from 3 representative experiments. 


\section{A}

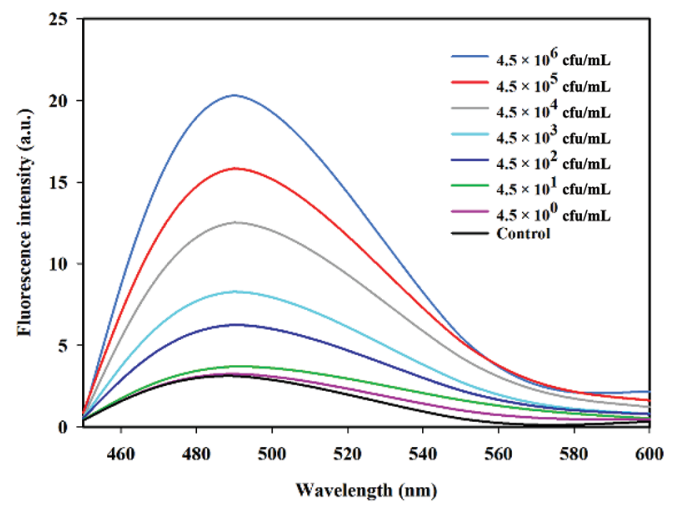

B

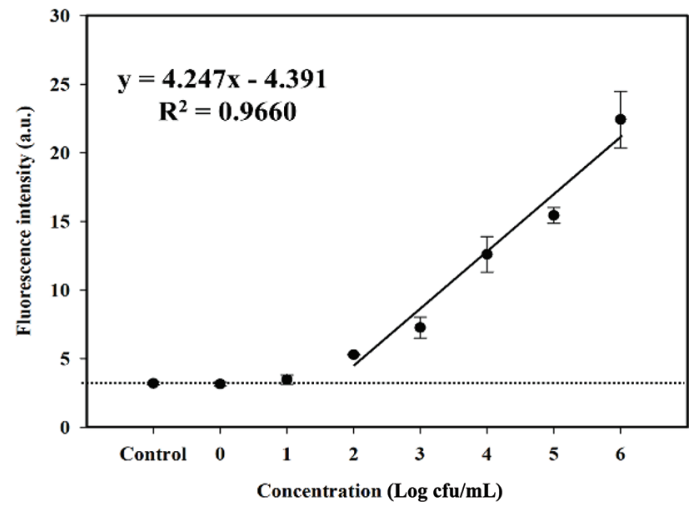

Figure 8. (A) Fluorescent signal response with different concentrations of Cronobacter sakazakii in spiked milk matrix ranging from $4.5 \times$ $10^{6}$ to $4.5 \times 10^{0} \mathrm{cfu} / \mathrm{mL}$. (B) The calibration curves of the $\log$ C. sakazakii concentrations $(\mathrm{cfu} / \mathrm{mL})$ with corresponding fluorescence intensities. The fluorescence intensities were measured at emission wavelength $=490 \mathrm{~nm}$. The dashed line represents the cut-off value. Error bars indicate the SD from 3 representative experiments. a.u. = arbitrary units.

8B) between fluorescent intensities and the concentrations of C. sakazakii was given by $\mathrm{y}=4.247 \mathrm{x}-4.391$ $\left(\mathrm{R}^{2}=0.9660\right)$, where $\mathrm{y}=$ the fluorescence intensity measured at $490 \mathrm{~nm}$ and $\mathrm{x}=$ the $\log$ concentration of C. sakazakii. Based on the cut-off value (mean $+3 \mathrm{SD}$ of the control group), the LOD of the proposed strategy in spiked milk matrix was $4.5 \times 10^{2} \mathrm{cfu} / \mathrm{mL}$. In our previous studies in foodborne pathogen detection ( $\mathrm{Yu}$ et al., 2019; Zhan et al., 2019) or other Cronobacter detection methods (Supplemental Table S2; https://doi.org/ 10.3168/jds.2019-17590) in past or recent years, assays based on antibody, PCR, and isothermal amplification were applied to the detection of Cronobacter. In these studies, antibody-based assays have the advantage of being rapid and convenient, but the preparation of antibodies specific to all species of Cronobacter is quite difficult. On the other hand, although other isothermal amplification-based assays such as LAMP possessed the advantages of high sensitivity, complicated primer design and annoying false-positive signal hampered the application of this method. The proposed strategy presented in this study did not require the preparation of anti-Cronobacter antibodies or design of complicated LAMP primers, it showed a comparable sensitivity $\left(10^{2}\right.$ $\mathrm{cfu} / \mathrm{mL}$ ) with high specificity, providing an alternative more convenient nucleic acid-based method for Cronobacter spp. detection in PIF.

\section{CONCLUSIONS}

A sensitive and highly specific AT-PCR + RCA universal sensor has been developed for the detection of Cronobacter spp. The sensor could detect as low as 4.3 $\times 10^{1} \mathrm{cfu} / \mathrm{mL}$ C. sakazakii in pure culture and $4.5 \times$ $10^{2} \mathrm{cfu} / \mathrm{mL}$ in spiked milk matrix. With a modification of the primers for AT-PCR, this sensor could serve as a universal platform for the detection of other pathogens. The strategy presents a simple and low-cost universal platform for sensitive and specific detection of foodborne pathogens especially in milk products.

\section{ACKNOWLEDGMENTS}

The work was supported by the National Key R\&D Program of China (no. 2018YFC1602500) and Research Foundation from State Key Laboratory of Food Science and Technology, Nanchang University, China (no. SKLF-ZZB-201720). The authors thank C. Man from Northeast Agricultural University (Harbin, China) for providing bacteria strain resources. The authors declare no conflict of interest.

\section{REFERENCES}

Chen, Q., Y. Li, T. Tao, X. Bie, F. Lu, and Z. Lu. 2017. Development and application of a sensitive, rapid, and reliable immunomagnetic separation-PCR detection method for Cronobacter spp. J. Dairy Sci. 100:961-969. https://doi.org/10.3168/jds.2016-11087.

Chinese National Standard. 2010. GB 10765-2010. China National Food Safety Standard, Ministry of Health of PRC, Beijing.

Cruz, A., J. Xicohtencatl-Cortes, B. González-Pedrajo, M. Bobadilla, C. Eslava, and I. Rosas. 2011. Virulence traits in Cronobacter species isolated from different sources. Can. J. Microbiol. 57:735-744. https://doi.org/10.1139/w11-063.

Cruz-Córdova, A., L. M. Rocha-Ramírez, S. A. Ochoa, B. GonzálezPedrajo, N. Espinosa, C. Eslava, U. Hernández-Chiñas, G. Mendoza-Hernández, A. Rodríguez-Leviz, P. Valencia-Mayoral, S. Sadowinski-Pine, R. Hernández-Castro, I. Estrada-García, O. MuñozHernández, I. Rosas, and J. Xicohtencatl-Cortes. 2012. Flagella from five Cronobacter species induce pro-inflammatory cytokines in macrophage derivatives from human monocytes. PLoS One 7:e52091. https://doi.org/10.1371/journal.pone.0052091.

Deng, K., C. Li, H. Huang, and X. Li. 2017. Rolling circle amplification based on signal-enhanced electrochemical DNA sensor for 
ultrasensitive transcription factor detection. Sens. Actuators B Chem. 238:1302-1308. https://doi.org/10.1016/j.snb.2016.09.107.

Fan, H., B. Long, X. Wu, and Y. Bai. 2012. Development of a loopmediated isothermal amplification assay for sensitive and rapid detection of Cronobacter sakazakii. Foodborne Pathog. Dis. 9:11111118. https://doi.org/10.1089/fpd.2012.1193.

Farmer, J. J., M. A. Asbury, F. W. Hickman, and D. J. Brenner. 1980 Enterobacter sakazakii: A new species of "Enterobacteriaceae" isolated from clinical specimens. Int. J. Syst. Bacteriol. 30:569-584. https://doi.org/10.1099/00207713-30-3-569.

Fei, P., C. Man, B. Lou, S. J. Forsythe, Y. Chai, R. Li, J. Niu, and Y. Jiang. 2015. Genotyping and source tracking of Cronobacter sakazakii and C. malonaticus isolates from powdered infant formula and an infant formula production factory in China. Appl. Environ. Microbiol. 81:5430-5439. https://doi.org/10.1128/AEM.01390-15.

Hu, L., L. M. Ma, S. Zheng, X. He, T. S. Hammack, E. W. Brown, and G. Zhang. 2018a. Development of a novel loop-mediated isothermal amplification (LAMP) assay for the detection of Salmonella ser. Enteritidis from egg products. Food Control 88:190-197. https: //doi.org/10.1016/j.foodcont.2018.01.006.

Hu, S., Y. Yu, X. Wu, X. Xia, X. Xiao, and H. Wu. 2018b. Simultaneous detection and identification of pathogenic Cronobacter species by high-resolution melting analysis in powdered infant formulas. Int. J. Dairy Technol. 71:253-263. https://doi.org/10.1111/1471 $-0307.12410$

Huang, J., X. Y. Li, Y. C. Du, L. N. Zhang, K. K. Liu, L. N. Zhu, and D. M. Kong. 2017. Sensitive fluorescent detection of DNA methyltransferase using nicking endonuclease-mediated multiple primerslike rolling circle amplification. Biosens. Bioelectron. 91:417-423. https://doi.org/10.1016/j.bios.2016.12.061.

Huang, R., L. He, Y. Xia, H. Xu, C. Liu, H. Xie, S. Wang, L. Peng, Y. Liu, Y. Liu, N. He, and Z. Li. 2019. A sensitive aptasensor based on a hemin/G-quadruplex-assisted signal amplification strategy for electrochemical detection of gastric cancer exosomes. Small 15:1900735. https://doi.org/10.1002/smll.201900735.

Hunter, C. J., M. Petrosyan, H. R. Ford, and N. V. Prasadarao. 2008 Enterobacter sakazakii: An emerging pathogen in infants and neonates. Surg. Infect. (Larchmt.) 9:533-539. https://doi.org/10 .1089 /sur.2008.006

Iversen, C., A. Lehner, N. Mullane, E. Bidlas, I. Cleenwerck, J. Marugg, S. Fanning, R. Stephan, and H. Joosten. 2007. The taxonomy of Enterobacter sakazakii: Proposal of a new genus Cronobacter gen. nov. and descriptions of Cronobacter sakazakii comb. nov. Cronobacter sakazakii ssp. sakazakii, comb. nov., Cronobacter sakazakii ssp. malonaticus ssp. nov., Cronobacter turicensis sp. nov., Cronobacter muytjensii sp. nov., Cronobacter dublinensis sp. nov. and Cronobacter genomospecies 1. BMC Evol. Biol. 7:64. https://doi org/10.1186/1471-2148-7-64.

Kumar, S., G. Stecher, M. Li, C. Knyaz, and K. Tamura. 2018. MEGA $\mathrm{X}$ : Molecular evolutionary genetics analysis across computing platforms. Mol. Biol. Evol. 35:1547-1549. https://doi.org/10.1093/ molbev/msy096.

Liang, T., P. Zhou, B. Zhou, Q. Xu, Z. Zhou, X. Wu, Z. P. Aguilar, and H. Xu. 2019. Simultaneous quantitative detection of viable Escherichia coli O157:H7, Cronobacter spp., and Salmonella spp. using sodium deoxycholate-propidium monoazide with multiplex real-time PCR. J. Dairy Sci. 102:2954-2965. https://doi.org/10 .3168/jds.2018-15736.

Liu, F., H. Liu, Y. Liao, J. Wei, X. Zhou, and D. Xing. 2015. Multiplex detection and genotyping of pathogenic bacteria on paper-based biosensor with a novel universal primer mediated asymmetric PCR. Biosens. Bioelectron. 74:778-785. https://doi.org/10.1016/ j.bios.2015.06.054.

Liu, M., J. Song, S. Shuang, C. Dong, J. D. Brennan, and Y. Li. 2014. A graphene-based biosensing platform based on the release of DNA probes and rolling circle amplification. ACS Nano 8:55645573. https://doi.org/10.1021/nn5007418.

Liu, S., Y. Geng, L. Liu, X. Sun, J. Shao, B. Han, J. Wang, and K. Tan. 2018. Development of an isothermal amplification-based assay for the rapid detection of Cronobacter spp. J. Dairy Sci. 101:4914-4922. https://doi.org/10.3168/jds.2017-13931.
Low, K. F., A. Karimah, and C. Y. Yean. 2013. A thermostabilized magnetogenosensing assay for DNA sequence-specific detection and quantification of Vibrio cholerae. Biosens. Bioelectron. 47:3844. https://doi.org/10.1016/j.bios.2013.03.004.

Mohanty, J., N. Barooah, V. Dhamodharan, S. Harikrishna, P. I. Pradeepkumar, and A. C. Bhasikuttan. 2013. Thioflavin T as an efficient inducer and selective fluorescent sensor for the human telomeric G-quadruplex DNA. J. Am. Chem. Soc. 135:367-376. https://doi.org/10.1021/ja309588h.

Ogrodzki, P., and S. Forsythe. 2015. Capsular profiling of the Cronobacter genus and the association of specific Cronobacter sakazakii and C. malonaticus capsule types with neonatal meningitis and necrotizing enterocolitis. BMC Genomics 16:758. https://doi.org/ 10.1186/s12864-015-1960-z.

Pan, R., Y. Jiang, L. Sun, R. Wang, K. Zhuang, Y. Zhao, H. Wang, M. A. Ali, H. Xu, and C. Man. 2018. Gold nanoparticle-based enhanced lateral flow immunoassay for detection of Cronobacter sakazakii in powdered infant formula. J. Dairy Sci. 101:3835-3843. https://doi.org/10.3168/jds.2017-14265.

Pei, X. Y., L. Yan, J. H. Zhu, N. Li, Y. C. Guo, P. Fu, H. Y. Jia, X. L. Zhang, X. R. Yang, and D. J. Yang. 2016. The survey of Cronobacter spp. (formerly Enterbacter sakazakii) in infant and follow-up powdered formula in China in 2012. Biomed. Environ. Sci. 29:99-106. https://doi.org/10.3967/bes2016.011.

Pierce, K. E., J. A. Sanchez, J. E. Rice, and L. J. Wangh. 2005. Linear-after-the-exponential (LATE)-PCR: Primer design criteria for high yields of specific single-stranded DNA and improved real-time detection. Proc. Natl. Acad. Sci. USA 102:8609-8614. https://doi .org/10.1073/pnas.0501946102.

Qin, Y., S. Liao, Y. Huang, J. Zhao, and S. Zhao. 2018. Ultrasensitive fluorescent detection of nucleic acids based on label-free enzymatic-assisted cascade signal amplification. Anal. Chim. Acta 1039:91-97. https://doi.org/10.1016/j.aca.2018.07.038.

Qing, T., X. He, D. He, X. Ye, J. Shangguan, J. Liu, B. Yuan, and K. Wang. 2017. Dumbbell DNA-templated CuNPs as a nano-fluorescent probe for detection of enzymes involved in ligase-mediated DNA repair. Biosens. Bioelectron. 94:456-463. https://doi.org/10 $.1016 /$ j.bios.2017.03.035

Skovgaard, N. 2003. Microorganisms in Foods 7: Microbiological testing in food safety management. Int. J. Food Microbiol. 89:291-292. https://doi.org/10.1016/S0168-1605(03)00163-6.

Smolina, I. V., V. V. Demidov, C. R. Cantor, and N. E. Broude. 2004. Real-time monitoring of branched rolling-circle DNA amplification with peptide nucleic acid beacon. Anal. Biochem. 335:326-329. https://doi.org/10.1016/j.ab.2004.07.022.

Song, X., S. Shukla, and M. Kim. 2018. Detection of Cronobacter species in powdered infant formula using immunoliposome-based immunomagnetic concentration and separation assay. Food Microbiol. 72:23-30. https://doi.org/10.1016/j.fm.2017.11.002.

Tang, Y., B. Lu, Z. Zhu, and B. Li. 2017. Establishment of a universal and rational gene detection strategy through three-way junctionbased remote transduction. Chem. Sci. (Camb.) 9:760-769. https: //doi.org/10.1039/C7SC03190D.

Thomas, D. C. G. A. Nardone, and S. K. Randall. 1999. Amplification of padlock probes for DNA diagnostics by cascade rolling circle amplification or the polymerase chain reaction. Arch. Pathol. Lab. Med. 123:1170-1176.

Tian, J., K. Huang, Y. Luo, L. Zhu, Y. Xu, and W. Xu. 2018. Visual single cell detection of dual-pathogens based on multiplex super PCR (MS-PCR) and asymmetric tailing HCR (AT-HCR). Sens Actuators B Chem. 260:870-876. https://doi.org/10.1016/j.snb .2018.01.017.

Urmenyi, A. M. C., and A. White Franklin. 1961. Neonatal death from pigmented coliform infection. Lancet 1:313-315. https://doi.org/ 10.1016/S0140-6736(61)91481-7.

Wang, J., H. Li, T. Li, and L. Ling. 2018. Determination of bacterial DNA based on catalytic oxidation of cysteine by G-quadruplex DNAzyme generated from asymmetric PCR: Application to the colorimetric detection of Staphylococcus aureus. Microchim. Acta 185:410. https://doi.org/10.1007/s00604-018-2935-y. 
Wooddell, C. I., and R. R. Burgess. 1996. Use of asymmetric PCR to generate long primers and single-stranded DNA for incorporating cross-linking analogs into specific sites in a DNA probe. Genome Res. 6:886-892. https://doi.org/10.1101/gr.6.9.886.

Xu, Y. G., L. M. Sun, Y. S. Wang, P. P. Chen, Z. M. Liu, Y. J. Li, and L. J. Tang. 2017. Simultaneous detection of Vibrio cholerae, Vibrio alginolyticus, Vibrio parahaemolyticus and Vibrio vulnificus in seafood using dual priming oligonucleotide (DPO) system-based multiplex PCR assay. Food Control 71:64-70. https://doi.org/10 .1016/j.foodcont.2016.06.024.

Yang, Z. Z., Z.-B Wen, X. Peng, Y. Q. Chai, W.-B. Liang, and R. Yuan. 2019. A novel fluorescent assay for the ultrasensitive detection of miRNA-21 with the use of G-quadruplex structures as an immobilization material for a signal indicator. Chem. Commun. (Camb.) 55:6453-6456. https://doi.org/10.1039/C9CC01850F.

Yu, S., Y. Tang, M. Yan, Z. P. Aguilar, W. Lai, and H. Xu. 2019. A fluorescent cascade amplification method for sensitive detection of Salmonella based on magnetic $\mathrm{Fe}_{3} \mathrm{O}_{4}$ nanoparticles and hybridization chain reaction. Sens. Actuators B Chem. 279:31-37. https:// doi.org/10.1016/j.snb.2018.09.091.

Zhan, Z., J. Liu, L. Yan, Z. P. Aguilar, and H. Xu. 2019. Sensitive fluorescent detection of Listeria monocytogenes by combining a universal asymmetric polymerase chain reaction with rolling circle amplification. J. Pharm. Biomed. Anal. 169:181-187. https://doi .org/10.1016/j.jpba.2019.03.016.

Zhang, L., Y. Zhang, L. Huang, Y. Zhang, Y. Li, S. Ding, and W. Cheng. 2019. Ultrasensitive biosensing of low abundance BRAF V600E mutation in real samples by coupling dual padlock-gapligase chain reaction with hyperbranched rolling circle amplification. Sens. Actuators B Chem. 287:111-117. https://doi.org/10 .1016/j.snb.2019.01.125.

Zhao, W., M. M. Ali, M. A. Brook, and Y. Li. 2008. Rolling circle amplification: Applications in nanotechnology and biodetection with functional nucleic acids. Angew. Chem. Int. Ed. Engl. 47:63306337. https://doi.org/10.1002/anie.200705982.

\section{ORCIDS}

Ju Liu ๑ https://orcid.org/0000-0002-5815-9482

Hengyi Xu ๑ https://orcid.org/0000-0003-0457-9665 